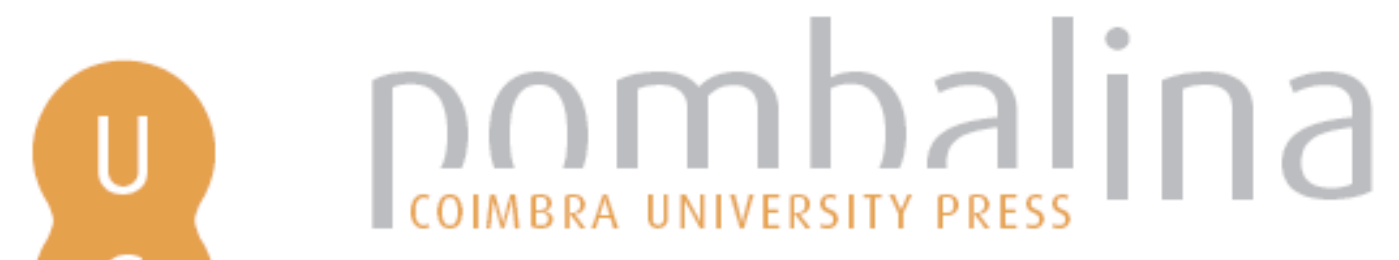

\title{
A rota dos cientistas
}

Autor(es): $\quad$ Serra, Isabel; Maia, Elisa

Publicado por: Imprensa da Universidade de Coimbra

URL

persistente: URI:http://hdl.handle.net/10316.2/32442

DOI: $\quad$ DOI:http://dx.doi.org/10.14195/978-989-26-0469-5_33

Accessed : $\quad$ 26-Apr-2023 08:46:35

A navegação consulta e descarregamento dos títulos inseridos nas Bibliotecas Digitais UC Digitalis, UC Pombalina e UC Impactum, pressupõem a aceitação plena e sem reservas dos Termos e Condições de Uso destas Bibliotecas Digitais, disponíveis em https://digitalis.uc.pt/pt-pt/termos.

Conforme exposto nos referidos Termos e Condições de Uso, o descarregamento de títulos de acesso restrito requer uma licença válida de autorização devendo o utilizador aceder ao(s) documento(s) a partir de um endereço de IP da instituição detentora da supramencionada licença.

Ao utilizador é apenas permitido o descarregamento para uso pessoal, pelo que o emprego do(s) título(s) descarregado(s) para outro fim, designadamente comercial, carece de autorização do respetivo autor ou editor da obra.

Na medida em que todas as obras da UC Digitalis se encontram protegidas pelo Código do Direito de Autor e Direitos Conexos e demais legislação aplicável, toda a cópia, parcial ou total, deste documento, nos casos em que é legalmente admitida, deverá conter ou fazer-se acompanhar por este aviso. 
Ana Leunar Pereira João Rui Pita

[ Coordenaçä̃ ]
Rotas da Natureza

Cientistas

Viagens

Expedifgũes

Instituip̧ües

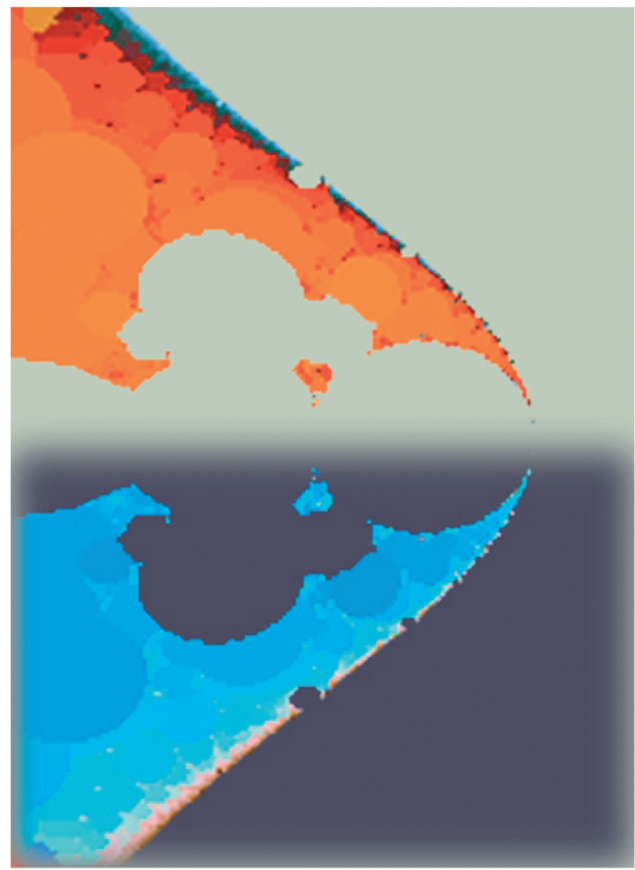




\section{Coordenaçáo Científica da Colecção Ciências e Culturas}

João Rui Pita e Ana Leonor Pereira

Os originais enviados são sujeitos a apreciação científica por referees

\section{Coordenação Editorial}

Maria João Padez Ferreira de Castro

\section{Edição}

Imprensa da Universidade de Coimbra

Email:impresauc@ci.uc.pt

URL: http://www.imp.uc.pt • Normas de publicação de colecçôes

\section{Design}

António Barros

Pré-Impressáo

António Resende

Imprensa da Universidade de Coimbra

\section{Capa}

António Barros, com imagem de E. M. de Melo e Castro, 2003 [Fractal original gerado no Fractint com tratamento no Photoshop 7.0]; Cortesia: António Barros

Impressão e Acabamento

SerSilito • Maia

\section{ISBN}

978-989-8074-12-6

\section{Depósito Legal}

Obra publicada com a colaboraçáo de:
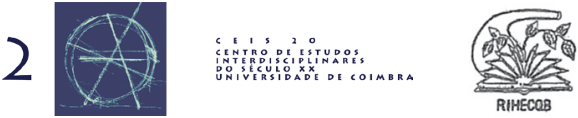

Obra publicada com o apoio de:

FCT Fundação para a Ciência e a Tecnologia

MINISTÉRIO DA CIÊNCIA, TECNOLOGIA E ENSINO SUPERTOR Portug

Programa Operacional Ciência, Tecnologia, Inovação do Quadro Comunitário de Apoio III
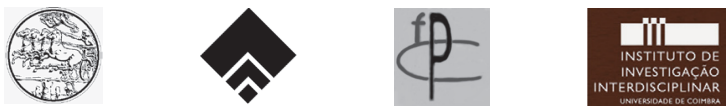

\section{Baxter}

(c) 2006, Imprensa da Universidade de Coimbra 
João Rui Pita

Ana Leonar Pereira

(Courdenação)

Rotas da Natureza

Cientistas

Viagens

Expediçũes

Instituiç̃̃es

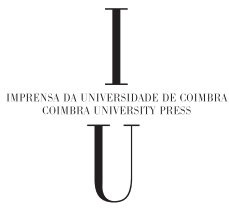

- colmbra 2006 
(Página deixada propositadamente em branco) 


\section{Isabel Serra e Elisa Maia}

Centro Interdisciplinar de Ciência, Tecnologia e Sociedade da Universidade de Lisboa, Portugal

\section{A rota dos Cientistas ${ }^{1}$}

A migração de cientistas teve efeitos consideráveis sobre a ciência portuguesa do século XX. A partir da década de vinte, um grande número de universitários vai para o estrangeiro, com carácter temporário ou definitivo, por razões de formação ou de ordem política. Acontece também, na mesma época, alguns cientistas estrangeiros imigrarem para Portugal. Os dois fenómenos serão aqui caracterizadas através de exemplos concretos e do seu enquadramento na situação da ciência em Portugal.

\section{As migrações de cientistas}

O fenómeno de migração de cientistas é tão antigo como a própria ciência. O primeiro representante da matemática grega, Thales, um viajante incansável, foi colher os seus conhecimentos de matemática no Egipto e na Babilónia. Desde essa época, as deambulações dos cientistas pelo mundo fora sucedem-se, multiplicam-se, e fazem história. As razões de tais viagens, com ou sem regresso ao lugar de origem, são as mais diversas. Procurar fontes de saber, vender a sua sapiência noutros lugares, ou fugir de perseguições políticas, são algumas dos motivos que, ao longo dos séculos, levaram alguns homens de ciência a emigrar.

Durante o século XX, essa emigração assume o aspecto de êxodo. Vários factores contribuem para esse fenómeno. Em primeiro lugar, há a transformação do trabalho de investigação científica ao longo desse século. A ciência deixa de ser um projecto individual, produzida no isolamento de um gabinete ou de um pequeno laboratório, muitas vezes financiado pelo próprio cientista, trabalhando sozinho ou rodeado de uns quantos discípulos. A ciência colectiviza-se, transfere-se para Universidades ou para Centros de Investigação, dirigidos por cientistas-gestores que devem saber escolher os projectos científicos adequados e também os investigadores capazes de os realizar. A angariação de cérebros passa então a ser feita à escala do planeta. É essa uma das causas da emigração de cientistas em grande escala, desde o século XX até aos nossos dias.

\footnotetext{
${ }^{1}$ Projecto POCTI, HCT/41185/2001.
} 
Outra razão para a transferência de cérebros é de ordem política. A chegada dos nazis ao poder, na Alemanha dos anos trinta, provocou o êxodo de grande número de talentos. A maior parte deles emigraram para a América do Norte, contribuindo para o notável desenvolvimento científico dos Estados Unidos no pós-guerra.

Em Portugal houve um fenómeno semelhante ao da Alemanha embora, evidentemente, em menor escala. O regime do Estado Novo foi responsável pela saída do país de muitos cientistas. Pode mesmo dizer-se que a ciência portuguesa foi delapidada à nascença por essa fuga de alguns dos maiores e mais activos investigadores dessa época.

\section{Quatro cientistas migrantes}

É difícil medir exactamente os efeitos desse êxodo, mas serão dados exemplos de casos ocorridos precisamente no momento em que começava a formar-se uma comunidade científica no país. Será também analisada, muito brevemente, a situação da Universidade e da investigação em Portugal na época em causa, com a finalidade de contextualizar o fenómeno da emigração dos nossos cientistas durante o século XX. Durante o mesmo período deu-se também a imigração de cientistas estrangeiros para Portugal, nalguns casos igualmente por razões de ordem política. Numericamente muito menos importante do que a perda, a aquisição de talentos científicos tornou-se relevante pelos seus efeitos positivos na ciência portuguesa pelo menos em dois casos, ambos na química: Kurt Jacobson, de origem alemã, cuja presença em Portugal determinou a emergência da Bioquímica no nosso país; Charles Lepierre, um francês que viveu em Portugal toda a sua carreira de investigador e que pode considerar-se um exemplo típico de uma certa maneira de fazer ciência. Serão aqui focados alguns aspectos da sua obra e da sua personalidade científica que permitem caracterizar um trajecto que, sem deixar de ser bem português, foi sem dúvida influenciado pela formação francesa.

\section{Emigração de cientistas portugueses no século XX}

A implantação da República originou a reforma das Universidades, criando assim condiçôes para a emergência da investigação científica em moldes modernos, como existia já noutros países europeus desde o século XIX. De facto, poucos meses após a proclamação da República, foram criadas as Universidades de Lisboa e Porto ${ }^{2}$ que compreendiam, entre outras, as Faculdades de Ciências. Nos objectivos da Universidade está explicitamente designado o de fazer progredir a ciência e iniciar os estudantes nos métodos de descoberta e invenção científica. As reformas do ensino da República resultam de um pensamento inovador que vê na ciência um fim em si mesma e já não um mero instrumento de preparação básica para carreiras militares, ministeriais ou liberais. Em vários documentos aparece explicitamente essa intenção. Para Pedro José

\footnotetext{
2 Decreto de 19 de Abril de 1911
} 
da Cunha a Faculdade de Ciências deveria tornar-se «não só num estabelecimento de ensino modelar, mas também num verdadeiro centro de estudos científicos, em que os trabalhos de investigação tomassem apreciável desenvolvimento» ${ }^{3}$.

Encontram-se inúmeros sinais da transformação que se preparava na Universidade Portuguesa e que, embora não tivesse chegado a ser verdadeiramente concretizada, existiu nas intenções e nos projectos de muitas personalidades. Um dos sinais de mudança na ciência portuguesa foi a criação da Junta Nacional de Educação em 19294, ${ }^{5}$. Este organismo destinava-se a financiar a investigação, sob a forma de bolsas de doutoramento no estrangeiro ou no país. Muitos cientistas portugueses fizeram a sua pós-graduação à custa dessas bolsas de estudo. Esses investigadores, uma vez regressados a Portugal, dinamizaram programas de investigação, fundaram revistas científicas e dirigiram a formação de novos investigadores. É nesse período que surgem as revistas especializadas, em Física a Portugaliae Physica, e em Matemática a Portugaliae Mathematica que ainda hoje se publica.

Entre os que beneficiaram das bolsas da Junta contam-se alguns dos nossos cientistas migrantes. Tendo emigrado uma vez, embora temporariamente, para se especializar em centros e laboratórios estrangeiros, voltaram a fazê-lo mais tarde, definitivamente, porque as condições políticas em Portugal, entretanto alteradas, não permitiram a sua permanência em Portugal.

O caso de Manuel Valadares é representativo dessa geração de cientistas que aprendeu a fazer investigação no estrangeiro e que, ao regressar, lutou pela internacionalização da ciência portuguesa. Tendo feito doutoramento no Laboratório Curie, como aliás muitos outros portugueses ${ }^{6}$, ao regressar a Portugal, Manuel Valadares estabelece um programa de investigação para o Centro de Estudos de Física da Faculdade de Ciências de Lisboa. $\mathrm{Na}$ Gazeta de Física este físico português explicou as razões das suas escolhas ${ }^{7}$. Sem grandes meios materiais, mas com o apoio de Cyrillo Soares ${ }^{8}$, professor da Faculdade e fundador do Centro de Estudos de Física, Manuel Valadares faz investigação de grande qualidade. Os seus principais colaboradores nesse empreendimento são Aurélio Marques da Silva e Armando Gibert, também doutorados no estrangeiro com bolsas da Junta Nacional de Educação. Durante um período de mais de dez anos (entre 1933 e 1947) vários cientistas portugueses adquirem formação e doutoram-se no laboratório dirigido por Valadares. Em 1947 os três principais colaboradores do

\footnotetext{
${ }^{3}$ Pedro José da Cunha, "A Escola Poltitécnica de Lisboa - Breve Notícia Histórica», Lisboa, 1937, p. 83

${ }^{4}$ Monteiro, H., A Junta de Educação Nacional, Anais da Faculdade de Ciências do Porto, no 20, p. 248, Imprensa Portuguesa, Porto, 1935.

${ }^{5}$ Monteiro, H., A Junta de Educação Nacional, Anais da Faculdade de Ciências do Porto, no 21, pp. 51-53, Imprensa Portuguesa, Porto, 1936

${ }^{6}$ Kabzinska, K., Os estudantes do Laboratório Curie no Instituto do Rádio, em Paris, e os pioneiros do estudo do cancro em Portugal, Gazeta de Física, 12 (1989), p. 102.

${ }^{7}$ Valadares, Manuel, O Laboratório de Física da Faculdade de Ciência de Lisboa, sob a direcção do Prof. Dr. A. Cyrillo Soares e a investigação científica., Gazeta de Física, Vol. II, 1950, pp. 93-106.

${ }^{8}$ Gil, F. B.; Serra, I. e Peiriço, N. M., "Cyrillo Soares e a Ciência em Portugal», actas da XIV Reunião da Rede de Intercâmbios de História e Epistemologia das Ciências Químicas e Biológicas, S. Paulo, 2004 .
} 
Centro, aqui citados, são demitidos pelo Governo, por razões de ordem política. Manuel Valadares parte para França, onde continua a trabalhar em Física Nuclear e, tendo chegado a director de investigação no CNRS, permanece nesse país até ao fim da sua vida, em 1988. Assim se perdeu, para Portugal, um dos motores do processo de modernização da ciência no século XX.

Outros cientistas que emigraram por razóes de ordem política durante o regime do Estado Novo são os matemáticos Ruy Luís Gomes, Aniceto Monteiro, Hugo Ribeiro e Pilar Ribeiro, participantes do "movimento matemático» ${ }^{9}$ que lutava pela modernização do trabalho científico em matemática, em particular pela sua internacionalização. Esse movimento é assim interrompido, em grande parte pelo desaparecimento de muitos dos seus membros da cena científica portuguesa que passaram a alimentar outros «movimentos matemáticos». Ruy Luís Gomes no Brasil, Aniceto Monteiro na Argentina, onde fundou uma escola de matemáticos que adquiriu proeminência internacional.

De entre os cientistas portugueses afastados das instituições universitárias por razóes políticas, os que emigraram foram aqueles que continuaram a trabalhar para a ciência. Para os que não puderam ou não quiseram emigrar, a carreira científica tornou-se difícil ou mesmo impossível. Foi o caso de Aurélio Marques da Silva, considerado um muito brilhante investigador mas que nunca mais fez investigação científica, depois de $1947^{10}$.

Existem, para além da tentativa de estruturação do trabalho de investigação científica, outros indicadores que traduzem o aparecimento de uma consciência colectiva sobre a importância da ciência, no Portugal dos anos trinta e quarenta do século XX. Os discursos e comunicações nos congressos científicos e noutros actos públicos são testemunhos dessa consciência. Ferreira da Silva (1853-1923), Químico, lente de Química Orgânica e Analítica na Academia Politécnica e depois na Faculdade de Ciências do Porto, fundador do Laboratório Municipal do Porto, escreve ${ }^{11}$ que a ciência é "civilisadora», "educadora», "emancipadora» e "constitui um princípio de concordia» entre os homens, "não é só porque cria riquezas, porque fomenta os progressos materiais", mas por todas as virtudes apontadas, a ciência "é verdadeiramente a benfeitora da humanidade».

Outros sinais desse "despertar para a ciência» são as Universidades Populares e as diversas revistas de divulgação científica. Nas áreas da Física e da Matemática surgem duas revistas: a Gazeta de Física e a Gazeta de Matemática que, embora com várias interrupçôes durante a sua existência, ainda hoje se publicam.

As purgas políticas na Universidade e o afastamento de grande número de homens de cultura e de ciência, provocaram um abrandamento da vida intelectual e científica do país. No entanto, as estruturas criadas pelas reformas republicanas continuavam a

\footnotetext{
${ }^{9}$ Gil, F. B., Núcleo de Matemática, Física e Quimica: uma contribuição efémera para o movimento científico português, Boletim da Sociedade Portuguesa de Matemática, 49, 2003, pp. 77-92

${ }^{10}$ Pereira, A. E Serra, I., La Physique et le Pouvoir Politique au Portugal dans les années 40», Proceedings of the XX $X^{\text {th }}$ International Congress of History of Science, Vol. I, pp. 181-189, 1997.

${ }^{11}$ Silva, Ferreira da, "A importância e dignidade da sciencia e as exigencias da cultura scientifica», Anais da Academia Politécnica do Porto, no 6 (1911) (discurso pronunciado na sessão de abertura solene da Universidade do Porto no ano lectivo 1911-1912)
} 
existir. Embora privados de alguns dos seus investigadores mais activos e talentosos, o país tinha acordado para a moderna investigação científica. Os Congressos LusoEspanhóis para o Progresso das Ciências continuaram a realizar-se ${ }^{12}$. Todas essas circunstâncias prepararam a grande transformação da ciência portuguesa que se acabaria por se dar durante os anos setenta e oitenta do século XX, apesar das restriçóes em que foi mantida durante o regime do Estado Novo.

\section{Charles Lepierre e Roberto Duarte Silva}

Em Portugal a abertura à ciência europeia havia começado mesmo antes das reforma republicana do ensino superior. É exemplo dessa modernização a Escola Politécnica ${ }^{13}$, onde alguns dos professores, entre os quais o já citado Pedro José da Cunha, realizaram trabalho de investigação e também se pronunciaram pela necessidade de a estimular.

Na Química destaca-se José Júlio Rodrigues responsável, entre outras realizaçōes, pela montagem de um laboratório exemplar - O Laboratório de Química Mineral da Escola Politécnica ${ }^{14}$. A necessidade de encontrar pessoal qualificado para o Laboratório levou este químico português a convidar Charles Lepierre para trabalhar em Portugal. O contacto com o então jovem francês foi feito através de Roberto Duarte Silva (!837-1889) um químico português, professor de Lepierre na École de Physique et Chimie Industrielles. Contratado pelo Governo Português, em 1888, como chefe de trabalhos de química da Escola Politécnica e também preparador de tecnologia química no Instituto Industrial, Lepierre permaneceu em Lisboa até 1889. Foi então para Coimbra onde ensinou primeiro na Escola Brotero e depois, até 1911, no Laboratório de Microbiologia da Universidade. Nesse ano regressou a Lisboa para ensinar no Instituto Superior Técnico, cuja recente criação fizera parte das reformas promovidas pelo regime republicano. Foi professor no Instituto durante vinte e seis anos e, a partir de 1919 ensinou também no Instituto de Hidrologia. Nessa altura os seus trabalhos em análise de águas eram já bem conhecidos. Foi também director do Laboratório do Instituto Português de Conservas de Peixe, cargo que desempenhou até à sua morte, em 1945.

A obra científica de Charles Lepierre é extensa e variada, repartindo-se por diversas áreas: Química analítica, Química Mineral, Bromatologia, Hidrologia e Bacteriologia. Trabalhou para sectores importantes da economia portuguesa, tal como as águas minero-medicinais, as conservas de peixe e o azeite. Publicou cerca de cento e vinte artigos, a maioria dos quais «têm atrás de si trabalho experimental próprio, por ele feito, ou executado sob a sua orientação e inspiração» ${ }^{15}$.

\footnotetext{
${ }^{12}$ Estes Congressos eram uma realização conjunta da Associação Espanhola Para o Progresso das Ciências, constituída em 1915 e da sua congénere Portuguesa, fundada em 1921.

${ }^{13}$ Cunha, Pedro José da, «A Escola Politécnica de Lisboa - Breve Notícia Histórica», Lisboa, 1937.

${ }^{14}$ Ana Luísa Janeira, Maria Elisa Maia, Pilar Pereira, Ed., O Laboratório de Química Mineral da Escola Politécnica de Lisboa, Livraria Escolar Editora, Lisboa, 1996.

${ }^{15}$ Carvalho, H., A obra cientifica de Charles Lepierre, Memórias da Academia das Ciências, Classe de Ciências, tomo V, 1947, pp. 21-46.
} 
Charles Lepierre, ao contrário do que acontece com muitos cientistas em fim de carreira, não produziu trabalhos ligados à História ou à organização do ensino e da investigação. No entanto deixou alguns artigos dedicados a personalidades da ciência que conheceu pessoalmente, todos eles seus mestres. Esses artigos, escritos com o intuito de prestar homenagem, traduzem, ao mesmo tempo, as concepçôes do autor sobre a ciência e sobre a maneira de a exercer a actividade científica. A forma e conteúdo dos seus textos permitem caracterizar o discurso sobre as ciências produzido em Portugal durante essa época. De facto, as palavras de Lepierre nesses artigos são típicas de um certo grupo de cientistas durante a primeira metade do século XX em Portugal. O químico francês, assumindo plenamente a sua migração, adopta a postura daqueles cientistas portugueses que reclamavam o reconhecimento da actividade de investigação.

Como já referimos anteriormente, Charles Lepierre veio para Portugal por intermédio de Roberto Duarte Silva, seu professor e por quem ele nutria enorme admiração. Dois artigos da Técnica e são testemunha do apreço do aluno pelo seu antigo mestre. No primeiro desses artigos ${ }^{16}$, em que Lepierre traça a história do seu professor, lê-se: «Depois de Lourenço é certamente Roberto Duarte Silva o químico português de maior nomeada; não exerceu infelizmente a sua actividade no solo natal». Roberto Duarte Silva é, tal como Charles Lepierre, um cientista que emigrou e fez toda a sua vida profissional no estrangeiro. O processo de identificação de Lepierre com o seu mestre é perceptível em todo o artigo. Intencionalmente ou não, ele vai buscando pequenas analogias, como a de ambos terem usado capelas como laboratórios, Duarte Silva em França, no palacete da Thorigny, Lepierre em Portugal, no antigo noviciado de Santa Cruz, (Coimbra).

Mais adiante no mesmo artigo conta Lepierre: "Roberto Duarte Silva tem a sua quota parte importante no desenvolvimento que essa Escola (École de Physique et Chimie Industrielles) devia ter no progresso das indústria físico-químicas em França. Em Portugal, não é demais dizê-lo, constatamos resultados análogos pela influência benéfica exercida na industria portuguesa pelos alunos do I.S.T.»: um outro ponto de encontro entre os dois químicos. De facto, o Instituto Superior Técnico é precisamente a escola onde Charles Lepierre foi professor durante vinte e seis anos, e onde desenvolveu, simultaneamente, uma actividade ligada à química aplicada.

Lepierre escreve de novo na Técnica sobre Roberto Duarte Silva, em 19377, no centenário do seu nascimento. Este artigo serviu também de base uma comunicação à Academia das Ciências e à Sociedade Portuguesa de Química e Física, quando das sessões de homenagem prestadas ao químico português na ocasião do centenário. Lepierre relata, em traços largos, a vida de Duarte Silva, referindo-se sobretudo à sua actividade científica nos laboratórios Wurtz e ao seu trabalho como professor. Expõe, por ordem cronológica, os estudos laboratoriais em química orgânica, realizados pelo químico, e os resultados obtidos, um dos quais foi, em conjunto com C. Friedel, a síntese da glicerina, em 1873. Charles Lepierre semeia essa descrição dos estudos de química de Duarte Silva, por pequenas observações acerca da qualidade do seu trabalho

\footnotetext{
${ }^{16}$ Lepierre, C., Roberto Duarte Silva, Técnica, no 13, pp. 129-131, 1928.

${ }^{17}$ Lepierre, C., Centenário de Roberto Duarte Silva, Técnica no 83, pp. 137-143, 1937.
} 
laboratorial. Refere também a interacção entre esse trabalho e o ensino, interacção que o químico português tinha sempre presente. Essas observações podem também aplicar-se ao próprio autor, segundo o que é possível deduzir das palavras de Herculano de Carvalho, alguns anos mais tarde ${ }^{18}$.

Ao abordar a questão de ensino da química, Charles Lepierre refere-se à teoria atómica, citando Wurtz: «A teoria atómica é apenas um hipótese, mas oferece um carácter tal de simplicidade e de generalidade que a torna verosímil, servindo de ligação entre as duas ciências que tratam da constitutição da matéria - a química e a física.» (...) «Por muito entusiasta que Wurtz fosse da teoria atómica não podia ele imaginar que trinta anos não seriam decorridos sem que se verificasse a realidade da existência dos átomos, a complexidade da sua estrutura, etc.».

A preocupação de Lepierre em tratar esta questão, e as citaçôes das palavras de Wurtz põem bem em evidência uma das qualidades científicas do próprio autor do artigo, neste caso, o cuidado em articular resultados experimentais com modelos teóricos.

\section{Dois mestres de Charles Lepierre}

A propósito de outro centenário de nascimento, o de Paul Schützenberger, Charles Lepierre fez uma conferência na Faculdade de Ciências, também publicada na Técnica $^{19}$. Tal como Duarte Silva, Schützenberger foi seu professor na École de Physique et Chimie Industrielles e é a ambos que deve a sua formação química. No seu artigo, depois de falar sobre os químicos da Escola Politécnica, Lepierre inicia o seu discurso sobre o homenageado afirmando, "Toda a obra científica de Schützenberger se ressente da influência do meio em que viveu quando rapaz: ligação intima da sciência pura e da técnica». Esta era sem dúvida uma questão importante para Charles Lepierre e na qual ele, ao longo da sua vida profissional, tomou uma posição bem clara, contrária à de muitos professores, em França que «julgavam rebaixar a sciência, tratando das suas aplicaçốes» ${ }^{20}$.

A descrição de Lepierre dos trabalhos de Schützenberger é acompanhada de comentários sobre as suas qualidades de investigador. «Ousadia das concepções», «rigor da técnica», invenção de métodos tornados "clássicos», "agudeza de interpretação» "permanência das conclusōes». É possível perceber que Charles Lepierre conhecia a obra do mestre, o seu significado na investigação em química e o seu impacto nas aplicações e que, inegavelmente, se identificava com a sua forma de fazer investigação.

Quase todos os investigadores têm os seus modelos e os seus heróis, figuras célebres da ciência e da cultura, que existiram por vezes num passado longínquo. Para Charles Lepierre, se atentarmos nos seus escritos de carácter histórico, os heróis científicos são homens do seu tempo. Primeiro os seus dois professores, Duarte Silva e Schützenberger, a quem "devia a sua formação química» e sobre os quais escreveu, não apenas com o intuito de homenagear mas também a de descrever qualidades e particularidades que

\footnotetext{
${ }^{18}$ Cf ref. ${ }^{\text {a }} 14$.

${ }^{19}$ Lepierre, C., Paul Schützenberger, Técnica, no 26, pp. 275-281, 1930.

${ }^{20}$ Ibid, p. 276.
} 
ele tomou como referência para a sua própria forma de fazer ciência. O que torna interessante esses textos, para quem está a estudar a vida científica de Charles Lepierre, é o processo de identificação do seu autor com os homenageados. Por um lado, é possível ver nas descrições feitas algumas das características do químico francês. Por outro, há também uma tomada de posição relativamente a questôes polémicas no meio científico. Uma dessas questões, atrás referida, foi a das aplicações da química, a propósito do artigo de Charles Lepierre sobre Schützenberger. Num outro artigo, este sobre Emile Duclaux ${ }^{21}$ (1840-1904), que também foi professor de Lepierre, a tomada de posição é ainda mais clara.

Emile Duclaux foi um físico francês cuja vida científica pode, segundo Lepierre, "dividir-se em duas partes: 1) a parte cientifica propriamente dita, criadora, que é bastante valiosa - 2) a parte crítica e analitica da obra de Pasteur, que é a mais importante e a mais duradoura da vida científica de Duclaux.» Depois de referir rapidamente a obra científica de Duclaux, Lepierre descreve, em três páginas, a luta daquele físico para divulgar a obra de Pasteur, obra que, nessa época não era ainda reconhecida. Uma das características dessa obra, que Duclaux descreve demoradamente no seu livro de 1896, l'Histoire d'un esprit, é a sua continuidade e a sua unidade. Não é só Duclaux que acha isso admirável, é também Charles Lepierre que admira Pasteur, através de Duclaux.

Escreve Lepierre: "Tal é a feição e o valor do "espírito" de Pasteur, exposto por Duclaux: partindo de fenómenos essencialmente materiais de física cristalográfica chega aos fenómenos mais complexos que o homem pode encarar: o problema da saúde, da doença - o problema da Vida!...». É também significativo que o autor destas palavras dê valor a essa especificidade da obra de Pasteur e divulgue o trabalho do divulgador.

Em 1938 a Academia das Ciências de Lisboa comemorou o 40ª aniversário da descoberta do rádio e, nessa ocasião Charles Lepierre fez uma comunicação sobre os Curie $^{22}$. Pierre Curie tinha sido também seu professor na École de Physique et Chimie Industrielles e, mais uma vez, a adesão de Charles Pierre a esta grande figura é também de ordem pessoal. Embora em relação a Pierre Curie a distância entre o aluno e o professor fosse maior do que nos casos de Duarte Silva e de Schützenberger, a admiração de Charles Lepierre assenta também num conhecimento directo e numa valorização de qualidades que implica proximidade de tempo e de lugar. Para o aluno, Lepierre, os estudos de Pierre Curie "sobre piezoelectricidade e magnetismo foram, no seu tempo, com raras excepçōes, mal apreciados dos físicos da época. Eram revolucionários demais para o conservatorismo da ciência de então.»(...) «Ele bem o sabia, mas não se incomodava com isso" ${ }^{23}$

Charles Lepierre, ao debruçar-se sobre a figura de Curie, chama a atenção sobre o aspecto anti-conservador da sua obra, tal como tinha feito no caso de Schützenberger. Outro aspecto focado no artigo é a recusa dos Curie em registar patentes das suas

${ }^{21}$ Lepierre, C., Emile Duclaux, Memórias da Academia das Ciências, classe de Ciências, tomo III, pp. 177-180, Lisboa, 1940.

${ }^{22}$ Lepierre, C., Pierre e Maria Curie, Memórias da Academia das Ciências, classe de Ciências, tomo II, pp. 197-210, Lisboa, 1938

23 Ibid, p. 201. 
descobertas. Embora este facto seja citado por quase todos os autores que escrevem sobre os Curie, é preciso reparar que Charles Lepierre fez a sua comunicação em 1938 e, nessa data, não se escrevia ainda muito sobre os Curie.

Os artigos aqui apresentadas não dão conta da extensa obra científica de Lepierre nas diversas áreas da Química Aplicada, tarefa essa já realizada por Herculano de Carvalho no seu citado artigo. Pretendeu-se apenas caracterizar o pensamento sobre a investigação científica de um cientista migrante, uma das personalidades que, durante a sua época, foi capaz de realizar obra, na ciência que se podia fazer em Portugal. De facto, dadas as severas restriçôes de ordem económica e a mentalidade dos responsáveis institucionais durante a primeira metade do século $\mathrm{XX}$, as áreas de trabalho na ciência estiveram sempre ligadas à actividade económica imediata. A existência, na Química, de aplicaçōes economicamente interessantes, tornou possível a Lepierre o desenvolvimento de um trabalho continuado em Química Analítica. Os seus artigos de memória levam a pensar que esse trabalho, embora de ciência aplicada, foi executado com o rigor, o método e a perfeição que costumam associar-se à ciência fundamental. 


\section{Colecçãa \\ 2 Ciências e Culturas Caimbra 2006}

